\title{
Surface charging, discharging and chemical modification at a sliding contact
}

\author{
Singh, Shailendra Vikram; Kusano, Yukihiro; Morgen, Per; Michelsen, Poul
}

Published in:

Journal of Applied Physics

Link to article, DOI:

$10.1063 / 1.3698311$

Publication date:

2012

Document Version

Publisher's PDF, also known as Version of record

Link back to DTU Orbit

Citation (APA):

Singh, S. V., Kusano, Y., Morgen, P., \& Michelsen, P. (2012). Surface charging, discharging and chemical modification at a sliding contact. Journal of Applied Physics, 111(8), 083501. https://doi.org/10.1063/1.3698311

\section{General rights}

Copyright and moral rights for the publications made accessible in the public portal are retained by the authors and/or other copyright owners and it is a condition of accessing publications that users recognise and abide by the legal requirements associated with these rights.

- Users may download and print one copy of any publication from the public portal for the purpose of private study or research.

- You may not further distribute the material or use it for any profit-making activity or commercial gain

- You may freely distribute the URL identifying the publication in the public portal 


\section{AIP Applied Physics}

\section{Surface charging, discharging and chemical modification at a sliding contact}

S. V. Singh, Y. Kusano, P. Morgen, and P. K. Michelsen

Citation: J. Appl. Phys. 111, 083501 (2012); doi: 10.1063/1.3698311

View online: http://dx.doi.org/10.1063/1.3698311

View Table of Contents: http://jap.aip.org/resource/1/JAPIAU/v111/i8

Published by the American Institute of Physics.

\section{Related Articles}

Impact of interfacial resistance switching on thermoelectric effect of Nb-doped $\mathrm{SrTiO} 3$ single crystalline J. Appl. Phys. 111, 063702 (2012)

Point Contact Andreev Reflection from Erbium: The role of external magnetic field and the sign of the spin polarization

J. Appl. Phys. 111, 07C519 (2012)

Theoretical study of point-contact Andreev reflection spectroscopy for ferromagnetic-metal/multi-band superconductor junctions

J. Appl. Phys. 111, 07C518 (2012)

Anomalous positive flatband voltage shifts in metal gate stacks containing rare-earth oxide capping layers Appl. Phys. Lett. 100, 102111 (2012)

The effects of organic material-treated $\mathrm{SiO} 2$ dielectric surfaces on the electrical characteristics of inorganic amorphous In-Ga-Zn-O thin film transistors

Appl. Phys. Lett. 100, 102110 (2012)

\section{Additional information on J. Appl. Phys.}

Journal Homepage: http://jap.aip.org/

Journal Information: http://jap.aip.org/about/about_the_journal

Top downloads: http://jap.aip.org/features/most_downloaded

Information for Authors: http://jap.aip.org/authors

\section{ADVERTISEMENT}
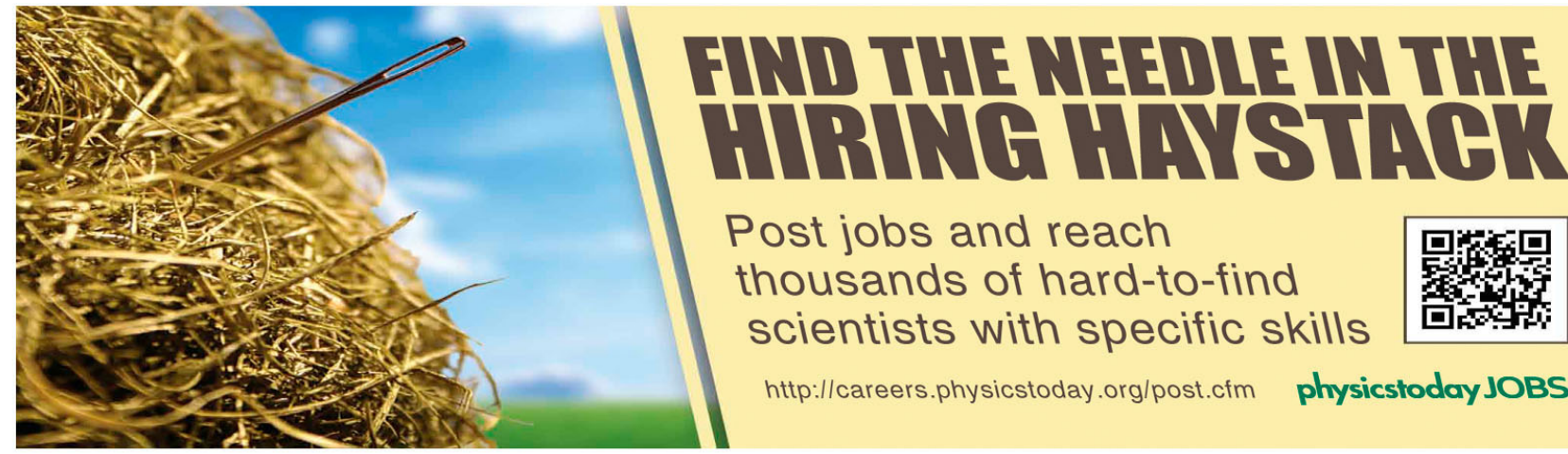

http://careers.physicstoday.org/post.cfm physicstodayJOBS 


\title{
Surface charging, discharging and chemical modification at a sliding contact
}

\author{
S. V. Singh, ${ }^{1, a)}$ Y. Kusano, ${ }^{1, b)}$ P. Morgen, ${ }^{2}$ and P. K. Michelsen ${ }^{3}$ \\ ${ }^{1}$ Department of Wind Energy, Section of Composites and Materials Mechanics, Technical University of \\ Denmark, Risф Campus, Frederiksborgvej 399, DK-4000 Roskilde, Denmark \\ ${ }^{2}$ Department of Physics, Chemistry and Pharmacy, University of Southern Denmark, DK-5230 Odense, Denmark \\ ${ }^{3}$ Department of Physics, Technical University of Denmark, P.O. Box 49, DK-4000 Roskilde, Denmark
}

(Received 6 January 2012; accepted 23 February 2012; published online 16 April 2012)

\begin{abstract}
Electrostatic charging, discharging, and consequent surface modification induced by sliding dissimilar surfaces have been studied. The surface-charge related phenomena were monitored by using a home-built capacitive, non-contact electrical probe, and the surface chemistry was studied by X-ray photoelectron spectroscopy (XPS). The experiments were performed on the disk surface of a ball-on-rotating-disk apparatus; using a glass disk and a Teflon (polytetrafluoroethylene) ball arrangement, and a polyester disks and a diamondlike carbon (DLC) coated steel ball arrangement. The capacitive probe is designed to perform highly resolved measurements, which is sensitive to relative change in charge density on the probed surface. For glass and Teflon arrangement, electrical measurements show that the ball track acquires non-uniform charging. Here not only the increase in charge density, but interestingly, increase in number of highly charged regions on the ball track was resolved. Threefold increase in the number of such highly charged regions per cycle was detected immediately before the gas breakdown-like incidences compared to that of other charge/discharge incidences at a fixed disk rotation speed. We are also able to comment on the behavior and the charge decay time in the ambient air-like condition, once the sliding contact is discontinued. XPS analysis showed a marginal deoxidation effect on the polyester disks due to the charging and discharging of the surfaces. Moreover, these XPS results clearly indicate that the wear and friction (sliding without charging) on the surface can be discarded from inducing such a deoxidation effect. (C) 2012 American Institute of Physics. [http://dx.doi.org/10.1063/1.3698311]
\end{abstract}

\section{INTRODUCTION}

Easy inline operation of atmospheric pressure plasma processing for surface modification has attracted significant interests. $^{1,2}$ Particularly, for the large surface treatments of materials like glass-fiber-reinforced polyester (GFRP used, e.g., for wind turbine blades), atmospheric pressure plasmas are being studied extensively. ${ }^{3-9}$ In order to make such treatments economically attractive, a distinct approach has been studied here. A sliding contact of dissimilar materials induces vivid physical (also referred to as tribophysical) phenomena due to mechanical and tribological activations. ${ }^{10-16}$ Among them tribocharging (electrostatic charging) and triboplasma (gas breakdown) generation have attracted considerable technological interest, e.g., for the studies related to wear, lubricant decomposition, and surface modification. ${ }^{13-22}$ The nature of tribophysical processes occurring highly depends on the intensity and temperature at the contact, shape and size of the contact, morphology, the bulk properties of the interacting materials, and surrounding of the interaction. ${ }^{11,20}$ Here, the intensity of the contact involves the load at the contact and the sliding speed. These tribological conditions affect triboelectrification and subsequent generation of triboplasma. These phenomena strongly depend on surface properties and can also induce surface modification.

The precise physical mechanism behind tribocharging is still unknown, although an empirical classification scheme

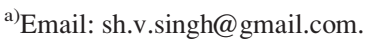

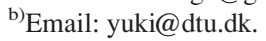

known as "triboelectric series" is available. ${ }^{20}$ The triboelectric series classifies distinct materials in the order of their tendency to acquire charge due to rubbing. Interestingly, the cause/origin of triboplasma generation has also been under debate and discussion. ${ }^{11,21-23}$ In this context, we believe that a plausible explanation for the ignition of a triboplasma is the generation of a high local electric field as a result of electrification by the charge separation of opposite signs on the sliding surfaces. ${ }^{21,22}$

Triboplasmas are often characterized by using optical emission spectroscopy. ${ }^{11,15,16,24-26}$ The optical emissions are reported to be observed mostly in the ultraviolet region. As these measurements were performed in ambient air, the emissions were dominated by nitrogen emission lines. Moreover, emissions originating from ambient $\mathrm{He}, \mathrm{O}_{2}, \mathrm{H}_{2}$, etc. are also reported. ${ }^{15,16}$ The spectroscopic results also show infrared emission corresponding to thermal radiation at the sliding contacts. Spectroscopic investigations of such systems give the evidence of the generation of triboplasma, but do not directly contribute to the understanding of the mechanisms of electrostatic charging and discharging. The surface tribocharging of such sliding contacts is often measured by using electrostatic probes. ${ }^{18,27}$ These probes are coupled to the circuits through non-contact arrangements to measure tribocharging on the rotating disks of pin- or ball-on-rotatingdisk experimental setups. Several works (see Refs. 13, 17, and 18) have been performed to study the electrostatic charging mainly to understand wear with and without lubricant and decomposition of the lubricant at sliding contacts. Typically bipolar charge signals have been reported for such 
systems. Relevant to this, Nakayama ${ }^{24}$ measured bipolar surface potential on the disk of such a sliding contact system, where bipolar fluctuations are attributed to the surface nonuniformity of the disk used. Earlier Singh et al. ${ }^{27}$ developed a non-contact probe (sensor) to study bipolar charging of powders and non-uniform charging of insulating solid surfaces. There (see Fig. 5 in Ref. 27), it is demonstrated that a moving unevenly charged surfaces relative to the probe generates a bipolar signal. These results are similar to the bipolar charging due to charge separation observed during powder handling. ${ }^{20,28}$

The above findings demonstrate that the observed bipolar signals due to charging/surface-potential on the rotating disk, of a pin or ball-on-disk setup, could mostly be attributed to non-uniform charging. Note that a bipolar signal, i.e., non-uniform charging, could be triggered due to the surface morphology, impurities, etc. ${ }^{11,24}$ Furthermore, these reports indicate that the tribocharge-magnitude increases with increasing loads on a pin/ball contact and increasing disk rotation speed. However, no clear evidence of the charge evolution (in terms of relative charge distribution) on the contact/charging/ball track with time is available. Note that such evolution could not be resolved in previous reports probably due to relatively large area sensor faces and slow data acquisition systems used. In addition the study of tribocharge evolution with time could independently indicate the phenomenon of gas breakdown.

A triboplasma can be generated by triboelectrification even without severe mechanical and tribological activation. ${ }^{15,16,21}$ Further to basic studies on triboplasma and surface tribocharging, we investigated possible application of surface modification of polyester by using a triboplasma. Surface modification studies are performed on polyester plates, which were brought in sliding contact with diamond-like carbon (DLC) coated steel balls. Note that glass-fiber-reinforced polyester (GFRP) materials are widely used for a variety of applications due to their high strength-to-weight ratios and corrosion resistance..$^{7-9}$ They are often jointed with components fabricated from similar or dissimilar types of materials using adhesives. They usually have smooth surfaces composed mostly of the polyester matrix materials with low surface energies, and thus a careful surface preparation is normally necessary before adhesion. GFRP surfaces were already plasma treated and studied in our group. ${ }^{3-9}$ These studies were performed by using dielectric barrier discharges and gliding arcs, but a successful implementation of triboplasma could lead to a broader and more economical applicability.

Here we report electrostatic charging and gas breakdown-like incidences for a sliding contact by utilizing a ball-on-rotating-disk (Teflon ball and glass-disk) setup. These phenomena were studied by monitoring the tribocharge evolution on the glass surface with time, on and across the ball track, by using a homebuilt capacitive noncontact electrostatic probe. The probe is designed to perform highly resolved (-spatial and -temporal) measurements. With this system, we are also able to comment on the behavior and the charge decay time in the ambient air-like conditioned surrounding, once the sliding contact is discontinued. In connection to the technological application of the triboplasma, we have been able to demonstrate the effect of triboplasma treatment of polyester surfaces. The polyester disks were treated by bringing them in sliding contact with diamond like carbon (DLC) coated steel balls. The surface chemistry of treated polyester disk was resolved by using X-ray photoelectron spectroscopy (XPS), which showed marginal surface modification.

\section{EXPERIMENTAL}

The schematic of the ball-on-rotating-disk experimental setup utilized is shown in Fig. 1(a). Here the sliding contact is created between the (unidirectional) rotating disk and the steady spherical ball. The disk can rotate up to $\mathrm{V}=1000$ rpm (rpm), and a normal force of up to $F_{N}=8 \mathrm{~N}$ could be applied at the contact. By moving the disk on the lateral axis, different radii (length) of rotation could be reached. All the experiments presented here were performed at a fixed disk rotation speed and normal load at the contact $\left(\mathrm{V}\right.$ and $\left.\mathrm{F}_{\mathrm{N}}\right)$, i.e., $600 \mathrm{rpm}(\mathrm{rpm})$ and $2 \mathrm{~N}$, respectively. One revolution corresponds to a length of around $6.25 \mathrm{~cm}$ (i.e., sliding speed of around $62.5 \mathrm{~cm} / \mathrm{s}$ ). A $10 \mathrm{~mm}$ diameter Teflon ball and a rotating partner made of $2 \mathrm{~mm}$ thick glass disk were used to study the basic phenomenon. Glass and Teflon are placed at two opposite sides of the triboelectric series, and thus the choice of these materials is ideal to achieve high opposite charges once brought to a sliding contact. ${ }^{20}$ Moreover, to study the possible application of a triboplasma for surface modifications of polyester disks, a $10 \mathrm{~mm}$ diameter DLC coated steel balls were brought in sliding contact.

To study tribocharging and gas breakdown effect, a homebuilt capacitive non-contact electrostatic probe was used; see Fig. 1(b). The probe was staged $0.8 \mathrm{~mm}$ above the disk and $180^{\circ}$ opposite to the ball as shown in Fig. 1(a). These measurements were performed by monitoring the tribocharging on the rotating glass disk. The probe is only sensitive to the change in the charge density, since it is capacitive. Hence, once the disk was at rest, the signal was

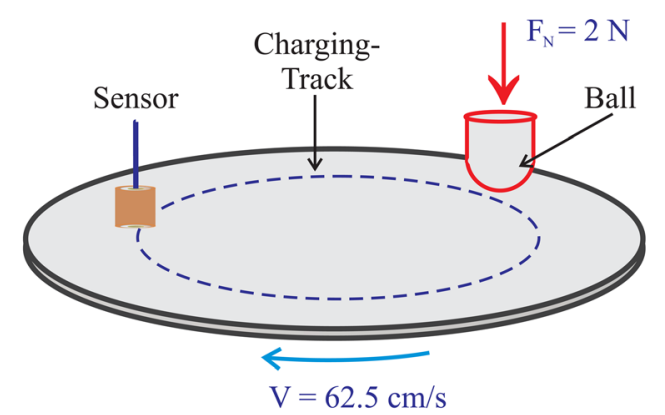

(a)

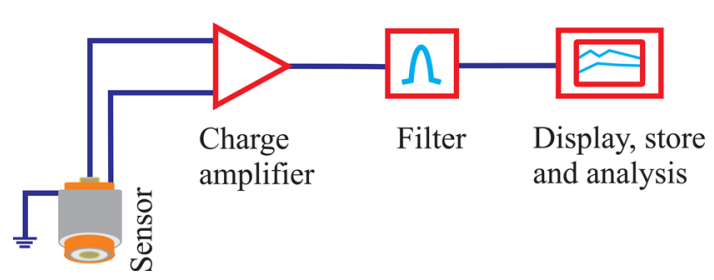

(b)

FIG. 1. Schematics of (a) ball-on-rotating-disk setup and (b) non-contact probe. 
zero. ${ }^{18}$ The probe contains a homebuilt sensor and a charge amplifier, which is directly connected to an oscilloscope.

The probe sensor is made up of an $8 \mathrm{~cm}$ long bulk coaxial cable RG402/U. Here a $0.9 \mathrm{~mm}$ diameter inner conductor is used as the probe tip (sensor face), which is separated by Teflon from a grounded $3.6 \mathrm{~mm}$ outer-diameter copper shield. The sensor circuit used is similar to a capacitor divider, which is surrounded by a grounded shield. The probe sensor is then connected to a two-stage charge amplifier. This two-stage charge amplifier is constructed using two similar types of operational-amplifiers (op-amps). One of the op-amps is used in the design/function of the first stage (charge-to-voltage conversion stage), whereas the other one is used for the second stage (output stage). The first stage transfers the input charge to a reference capacitor and produces an output voltage equal to the voltage across the reference capacitor. The second stage works as a unity gain buffer amplifier. It is used to transfer the original signal obtained from the first stage to a $50 \Omega$ output impedance level. This two-stage charge amplifier provides a frequency response up to 300 $\mathrm{MHz}$, sensitivity $0.45 \mathrm{~V} / \mathrm{pC}$, and rise-time $<30 \mathrm{~ns}$.

The probe sensor and the charge amplifier combination are then connected to a high speed oscilloscope (Tektronix DPO7104, bandwidth $1 \mathrm{GHz}$ and sample rate $20 \mathrm{GSa} / \mathrm{s})$. Through this combination high sample rates were achieved, and consequently highly resolved measurements could be performed on the ball track (here with a time resolution of up to $500 \mathrm{~ns}$ at a sample rate of $2 \mathrm{MSa} / \mathrm{s}$ ). Under such high sample rates, it is likely to get aliasing, if the sample rates are not chosen properly. To discard aliasing, the recorded signals were simultaneously cross-checked using low pass filters. The cut-off frequencies of the filters were chosen to be $1 / 2$ of the sample rate. Note that the probe signals presented here are not calibrated and hence only the trend could be studied from the sensor. The measured signals were bipolar, which will be later discussed in further details.

These measurements were performed in a conditioned box $\left(80 \% \mathrm{~N}_{2}, 20 \% \mathrm{O}_{2}, 35-45 \%\right.$ relative humidity at $\left.20^{\circ} \mathrm{C}\right)$. Moreover, in comparison to the conditioned box, no noticeable difference was observed in open air with relative humidity between 35 and $55 \%$ and at temperature between 20 and $22{ }^{\circ} \mathrm{C}$. For example, the signal strength was only 7 to $10 \%$ lower at high humidity (around 55\%) than at around 35\%.

The sliding contact materials, as far as basic studies are concerned, were chosen with the help of available triboelectric series with intent to achieve high opposite charges once the materials were brought in sliding contact. However, polyester disks were used to study surface modifications, where $10 \mathrm{~mm}$ diameter DLC coated steel balls were used as a sliding partner for the treatment. This set was chosen keeping in mind for the industrial applicability of GFRP and the tribological properties of DLC. In GFRP the reinforced glass fibers create rough surfaces, hence the triboplasma treatments were performed on the base polyester. The used 3 $\mathrm{mm}$ thick polyester disks were ultrasonically cleaned in de-ionized water for $2 \times 5 \mathrm{~min}$, acetone for $2 \times 5 \mathrm{~min}$ and in methanol for $5 \mathrm{~min}$ before plasma treatment.

The treated surfaces were studied by XPS. Data were collected using a double anode $(\mathrm{Mg} / \mathrm{Al})$ source, and for the present measurements the $\mathrm{Mg} \mathrm{K}_{\alpha}$ line with an energy of $1253.6 \mathrm{eV}$ was used, with a lateral resolution of $2 \mathrm{~mm}$ of the analyzer to study the changes in elemental compositions and the functional groups on the polyester surfaces. Atomic concentrations of all elements were calculated by determining the relevant integral peak intensities subtracting a Shirleytype background from the wide-scan spectra. A highresolution analysis was performed of the carbon $1 \mathrm{~s}(\mathrm{C} 1 \mathrm{~s})$ peak (pass energy $40 \mathrm{eV}$ ) acquired over 3 scans. The accuracy of the measurement is estimated to be better than $2 \%$. The binding energies were referred to the hydrocarbon component $(\mathrm{C}-\mathrm{C}, \mathrm{C}-\mathrm{H})$ at $285 \mathrm{eV}$. The narrow-scan spectra were de-convoluted through curve fitting, taking purely Gaussian components with linear background subtraction. The instrumental full-width at half-maximum (FWHM) for all peaks of $\mathrm{C} 1 \mathrm{~s}$ was $1.6 \mathrm{eV}$, which is the combined resolution of the spectrometer and the width of the X-ray source. The fitted components had larger widths than this. Some of the widening of the peaks is due to various energy-loss phenomena at the polymer surface. ${ }^{4,6}$

\section{RESULTS AND DISCUSSION}

Due to the exceptionally small sensing area and high sample rate of the data acquisition system, a fine spatial resolution on the ball track could be obtained with the probe. Principally, once a charged part passes the sensor face an opposite charge will be induced on the sensor active area. The current induced by the appearance of the opposite charge will be measured. Figure 2 demonstrates the bipolar current signal obtained by the probe during the sliding contact.

The probe is only sensitive to the change in the charge density, $\mathrm{d} q / \mathrm{d} s$, on the disk below the sensor face, where $s$ is the coordinate on the disk and $q$ is the charge picked by the sensor face (charge density). Once the disk was at rest, the signal observed was zero $(\mathrm{d} q / \mathrm{d} s=0)$. Thus, the bipolar signal corresponded to the local changes $(\mathrm{d} q / \mathrm{d} s)$ due to nonuniformity of the charge at the charging track. The nonuniformity could be created due to the preferential charging at some regions on the charging track. This preferential

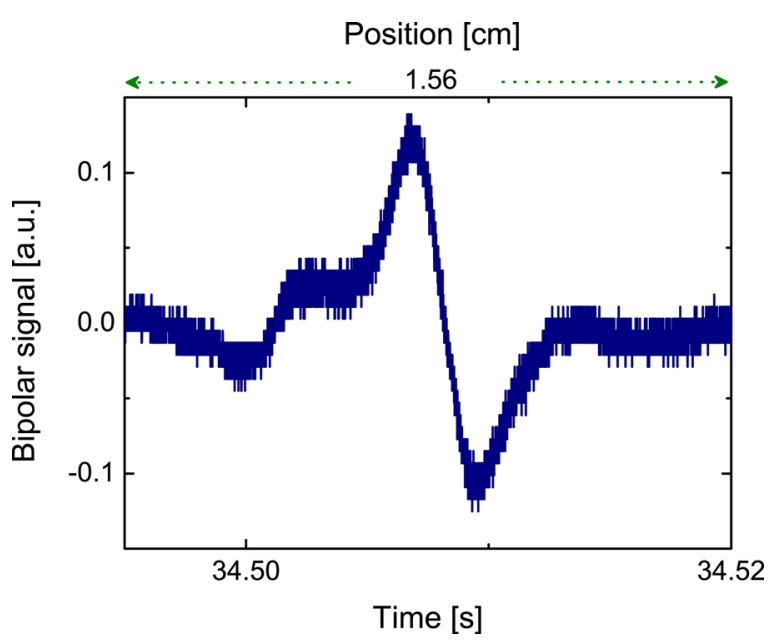

FIG. 2. Bipolar signal from the electrostatic probe. (Partially taken from Singh et al. (Ref. 19).) 
charging on the disk could depend on the surface morphology, impurities and running-in effects. The bipolar signal in this context is reported at several occasions, e.g., in Ref. 27 the bipolar signal is as a result of used array of alternate positive and negative charged spots, whereas in Ref. 28 it is due to the bipolar charging on the particles. Comparing to the bipolar signals reported in Refs. 27 and 28, differences in the magnitude of similar charges at adjacent points could also produce proportionate strengths of positive and negative fluctuations. In our sliding contact system of glass and Teflon, the triboelectric series ${ }^{20}$ indicates that the probed glass disk will accumulate positive charge. In Fig. 2, the positive currents (maxima) correspond to the accumulated positive charge on the disk, whereas the negative currents (minima) correspond to the adjacent uncharged or relatively less charged region. Hence, positive and negative currents indicate that the monitored location has higher and lower charge densities than the neighboring location monitored just before, respectively. Furthermore a positive peak immediately following a negative peak, as a bipolar signal, indicates an isolated highly positively charged region. It is essential to note here that any comments on increase/decrease in tribocharge level in the present work are mainly based on relative increase/decrease in highly charged regions compared to the neighboring less charged regions.

Identical to previous reports the bipolar signals obtained here were also dependent on the variations in the rotation speed of the disk, indicating non-uniform charging. ${ }^{24,28}$ One to six maxima and minima of such kind have been obtained per rotation corresponding to the number of highly charged regions during the sliding. This has been observed at different disk rotation speeds, i.e., $400 \mathrm{rpm}, 600 \mathrm{rpm}$ and $800 \mathrm{rpm}$ for applied normal loads of $1 \mathrm{~N}, 2 \mathrm{~N}$, and $5 \mathrm{~N}$ at the contact. The general trend of charge distribution on the ball tack at these distinct conditions was the same. Hence, here we focus on the results obtained at the fixed disk rotation speed of $600 \mathrm{rpm}$ with a fixed normal load of $2 \mathrm{~N}$ at the contact.

Figure 3 demonstrates the results of tribocharging due to sliding contact, which were performed by moving the probe in radial direction manually four times across the ball-disk contact (charging) track. The measured signal was bipolar

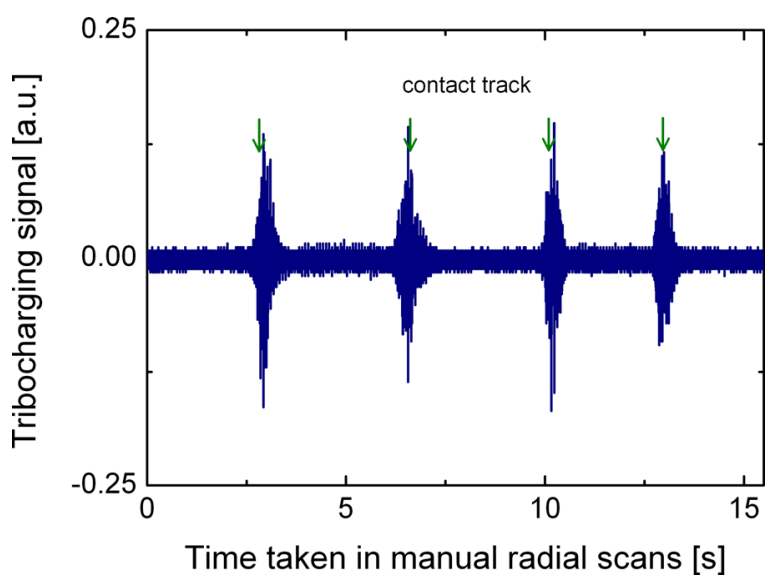

FIG. 3. Demonstration of surface charge distribution across-and-on the charging (ball-disk sliding contact) track. throughout above the rotating glass disk, whose intensity increases significantly once the face of the sensor passes above the charging track. The relatively low background bipolar signal observed off the ball track is probably due to the surface morphology. ${ }^{24}$ The dramatic difference in the magnitude of the signal reveals the increased charge level on the ball track. It also shows how the charge is confined within in the ball track. Notably, it also demonstrates the sensitivity of the probe. These measurements were performed by a ball, which was intentionally used for more than $500 \mathrm{~s}$. Due to the long scratching time, white powder-like debris had settled at the sides of the track, which however, did not influence the measurements significantly, as the peak of the signal was seen when the sensor passed around the center of the track. Only the floating dust, especially, those reaching the sensor face produced an extremely high (up to few hundred times of the original) instantaneous signal. To avoid dust accumulation and to sustain the ball-like shape, every set of measurements presented in the next sections was performed by using a virgin Teflon ball.

The further focus of the study was to investigate the non-uniform nature of the charging and its evolution during the sliding at the ball track. However, similar to previous reports for different combination of materials, our results of long (distance/time) measurements could also on a broader scale be divided into several regions. ${ }^{13,17,18}$ Among all, the region immediately after the start of the sliding contact was noticeable-dominated by running-in process. ${ }^{17}$ This initial sliding contact region lasted for around $20 \pm 3 \mathrm{~s}$. To achieve the similar running-in, virgin glass disks were used along with virgin balls. Figure 4 presents the running-in [initial part of Fig. 6].

Through several sets of measurements it was established that observed running-in always contained two distinctive segments. The first and initial segment was characterized by strong bipolar signal, probably dominated by strong charging due to initial changes on the surface morphology. This is the region where the fine features (roughness) of virgin "smooth" surfaces are probably rubbed off, and the sliding surfaces develop a new contact. ${ }^{29}$ This segment was always followed by a second low bipolar signal segment. In this low signal region, the smoothed (new) surfaces may develop large

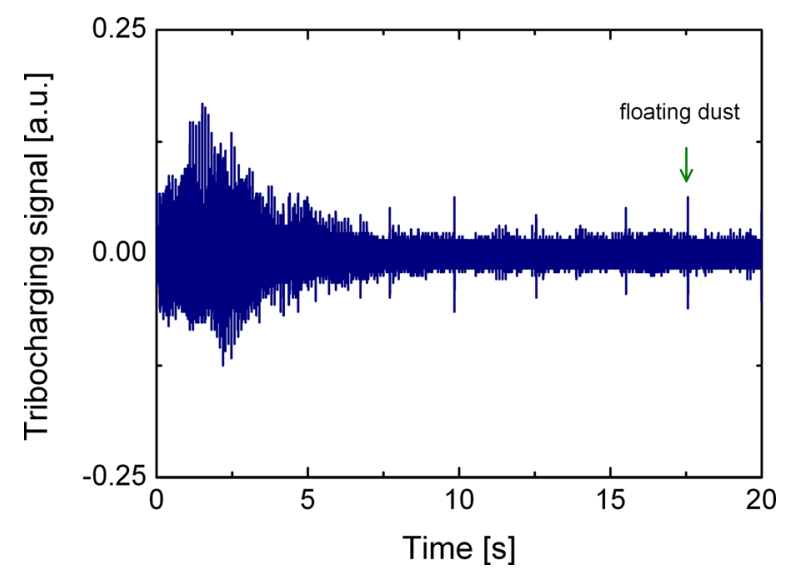

FIG. 4. Running-in effect; initial $20 \pm 3 \mathrm{~s}$ after the sliding contact is established (initial part of Fig. 6). 
contact areas, subsequently promoting tribocharging in the next region. The time frame of these two initial segments was not reproducible even for the similar loads and disk rotation speeds. These segments, and mainly the second one, were often dominated by dust formation. A strong tribocharging and the possible triboplasma were mainly generated after the running-in. We attempted to understand how tribocharge disappears (by neutralization, diffusion, etc.) under the chosen experimental conditions after the running-in, see Fig. 5.

Figure 5 demonstrates electrostatic charge neutralization in ambient air (-like environment chosen for the experiments) and/or neutralization/diffusion on or into the glass disk, once the sliding contact is terminated by elevating the ball from the disk. Region-A (recorded directly after the running-in) of the figure depicts high bipolar signal due to electrostatic tribocharging, which is measured when the ball is in sliding contact with the rotating glass disk. Whereas, region$\mathrm{B}$ of the figure depicts a slow discharging where the glass disk is still rotating but the sliding contact is instantly terminated by lifting-up the ball. Here the tribocharge decay halflife, $\mathrm{t}_{1 / 2}, \approx 0.7 \mathrm{~s}$ (corresponding to $\sim 44 \mathrm{~cm}$ ) was estimated. Finally, region- $\mathrm{C}$ is recorded when the disk is also at hold, where zero signal indicates the probe's insensitivity to stationary charges. Region-B can be highly influenced by the surrounding conditions, and by surface and bulk properties of the disk material. For example, in Teflon ball and sapphire disk combination, the decay half life for such experiments was around 10 seconds (results not shown). For glass-Teflon no significant difference could be resolved for region B by changing humidity (measured at $40 \%$ and 55\%). However, we did not try more extreme conditions.

For the glass-Teflon sliding contact in the conditioned environment, we believe that both the neutralization and the diffusion on or into the glass could be among the causes of the charge decay. It is very difficult to precisely comment on the main cause (e.g., see Refs. 30 and 31). Similar to the experiments depicted in Fig. 3 the lateral tribocharge distribution was studied for region-B as well when the contact was terminated. No evidence of lateral charge diffusion could be resolved. However, in this context we have observed a lateral

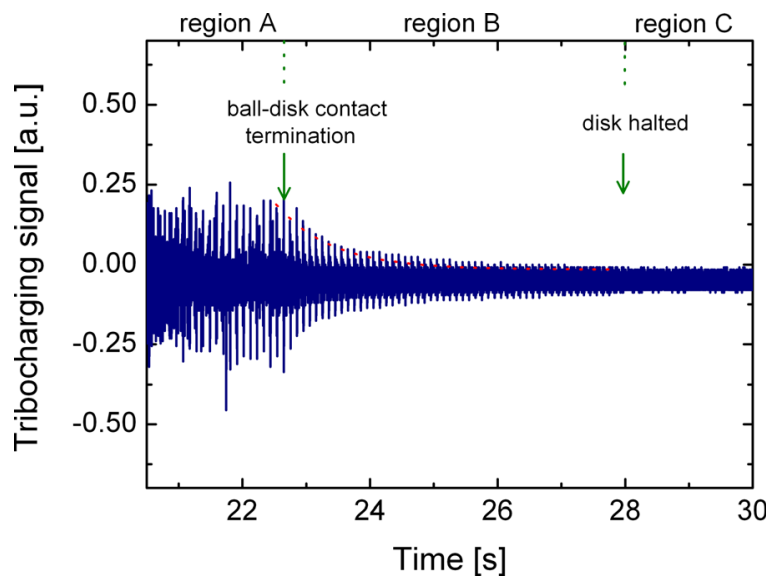

FIG. 5. Bipolar signal demonstrating: tribocharging (region-A); charge disappearance due to ball-disk contact termination (region-B); and finally when disk is also brought on halt, demonstrating probes insensitivity to stationary charge (region-C). (in the radial direction) diffusion of accumulated charge on rotating sapphire disk in contact with the Teflon ball (results not shown here). Moreover, this combination (sapphireTeflon) behaved entirely different and is out of the scope of this work. But it is important to note the difference in the resistivity $\sim 10^{15} \Omega$-cm of glass to $10^{19} \Omega$-cm of sapphire. It has been reported that the charge penetration depth is very sensitive to resistivity particularly for thin oxide films. The penetration depth in $\mathrm{SiO}_{2}$ was reported to be around $30 \mathrm{~nm}$, and $100 \mathrm{~nm}$ for $\mathrm{Al}_{2} \mathrm{O}_{3}$ films. ${ }^{32,33}$ Furthermore, the repeated contact (and/or rubbing) allows charges to penetrate into the bulk of the sample, for example by electrical conduction. ${ }^{30,34}$ This supports different natures of charging and discharging between glass and sapphire. Similarly, the surface energy can affect the water content at the surface, ${ }^{11,35}$ where water can act as a charge carrier, and consequently affect the charge neutralization. However, this issue could be negligible here in the case of glass and sapphire due to their very high (compared to water) surface energy. ${ }^{35}$ Precisely, the charge penetration depth, lateral diffusion, neutralization in air and their rate could also be influenced by the dielectric constant, surface energy, resistivity, and the charge attainability (triboelectric series) of the bulk material. In the present context, where no radial diffusion could be observed, these bulk, surface, and surrounding properties might favor charge diffusion into the glass compared to lateral charge diffusion. Due to the difference in charge level at distinct regions on the ball track (this issue will be discussed later), dispersion because of a generated electric field is also unavoidable. However, it is very difficult to identify as well as to quantify the main causes of neutralization of the accumulated tribocharge on a glass disk. Further dedicated research is needed for deeper understanding of these phenomena.

Here we extend our focus on the evolution of charge on the ball track. Several works have separately reported tribocharging by electrical probe measurements (e.g., Ref. 18), and triboplasma generation by emission (e.g., Ref. 22) for distinct sliding contacts. However, detailed tribocharge evolution on the ball track is still missing. In the literature, probably due to a large sensor face used and relatively slow data acquisition, even the abrupt changes due to probable microdischarge generation could not be resolved. Note that emission measurements on produced micro-discharges can only provide time-averaged information. In this connection, due to the highly resolved measurements and the use of a small sensor face, we have been able to resolve abrupt changes in the tribocharging as well as a change in the number of highly charged regions on the ball tack.

Figure 6 depicts a result of long (time/distance) sliding experiment, i.e., the region after the running-in (Fig. 4). In this region, the occasional electrostatic charging and discharging can be clearly seen. The increase in tribocharge level with time of interaction is indicated by the dotted lines guiding the eyes; starting at $20 \mathrm{~s}, 26.5 \mathrm{~s}, 30 \mathrm{~s}$, and $37.5 \mathrm{~s}$, respectively. (Note the difference in the slope of the dotted line, it indicates the difference in the rate of charging. No reproducibility on this could be obtained.) However in Fig. 6, the most striking events were where the continuous increase in charging (starting at $\sim 30 \mathrm{~s}$ ) was abruptly followed by significant decrease in 


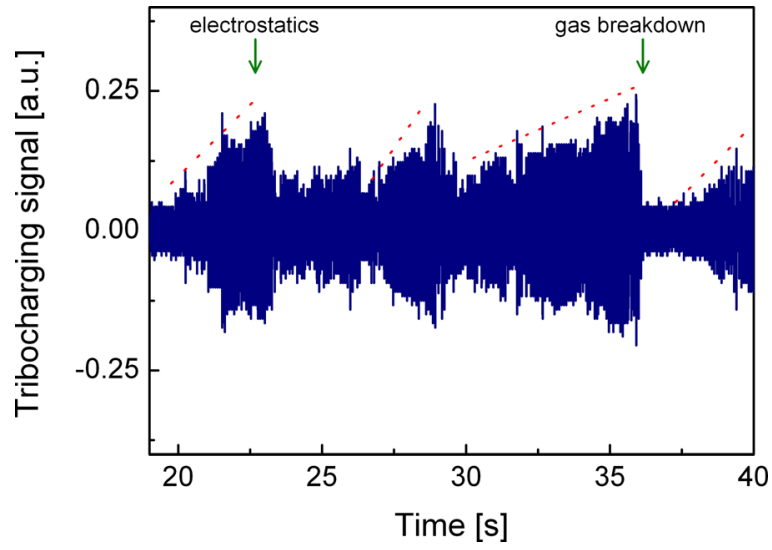

FIG. 6. Measurements after running-in demonstrating electrostatics and slow (at around $23.3 \mathrm{~s}$ and $28 \mathrm{~s}$ ) as well as instantaneous (at around $35.6 \mathrm{~s}$ ) charge decay. The data presented here (between $20 \mathrm{~s}$ and $40 \mathrm{~s}$ ) is a part of $100 \mathrm{~s}$ long measurement. Due to a huge data file presenting all data in one figure is practically impossible. However, all the relevant physical issues to be discuss here is present in this segment and in Fig. 4. (Partially taken from Singh et al. (Ref. 19).)

the signal intensity (at $\sim 35.6 \mathrm{~s}$ ). The slow discharging in the previous result (Fig. 5) indicates that any discontinuity in a sliding contact will not bring an instantaneous decrease in the bipolar signal intensity (charge level). Any abrupt decrease in charging (charge level) could only be explained by the process where the accumulated charge is neutralized effectively and promptly. We believe that the observed abrupt decrease in charge level in Fig. 6 at $\sim 35.6 \mathrm{~s}$ might be due to gas breakdown. The way of discharging after the peak at $\sim 35.6 \mathrm{~s}$ is distinctively different from that of at $\sim 23.3 \mathrm{~s}$ and $\sim 28 \mathrm{~s}$. As after $\sim 23.3 \mathrm{~s}$ and $\sim 28 \mathrm{~s}$, similar to Fig. 5, the charge decay is relatively slow $\left(\mathrm{t}_{1 / 2}\right.$ of $\sim 0.4 \mathrm{~s}$ to that of $\sim 0.1 \mathrm{~s}$ after $\left.35.6 \mathrm{~s}\right)$.

Though the strength of the bipolar signal has been comparable at around $23.3 \mathrm{~s}, 28 \mathrm{~s}$, and $35.6 \mathrm{~s}$; a thorough study reveals contrasting evolution of tribocharge on the ball track in the vicinity of these time frames. The tribocharge evolution close to $23.3 \mathrm{~s}$ and $28 \mathrm{~s}$ is contrastingly different to that of close to 35.6 s, see Fig. 7(a) and Fig. 7(b). Figures 7(a) and 7 (b) are zoom-in of Fig. 6 at $\sim 23.3 \mathrm{~s}$ and $\sim 35.6 \mathrm{~s}$, respectively. As the behavior at $23.3 \mathrm{~s}$ was almost similar to that of at $28 \mathrm{~s}$, only the region around $23.3 \mathrm{~s}$ is chosen. Comparison of graphs in Fig. 7(a) and Fig. 7(b) indicates that the number of bipolar current peaks increased almost threetimes per cycle before the abrupt breakdown at $\sim 35.6 \mathrm{~s}$. The number of bipolar current peaks indicates two adjacent regions with distinct level of charging on the ball track, whereas the positive strength of the signal indicates the relative increase in charge density of the highly charged regions. Including the small bipolar signals, one to three highly charged regions per cycle in Fig. 7(a) can be seen, whereas three to six highly charged regions per cycle in Fig. 7(b) are seen. The almost threefold increase in the number of bipolar current peaks per cycle demonstrates a proportionate increase in the highly charged regions on the track. Based on this we tentatively propose that the charge density has significantly increased along the ball track before the breakdown situation ( $\sim 35.6 \mathrm{~s})$ as compared to other slow decay mecha-

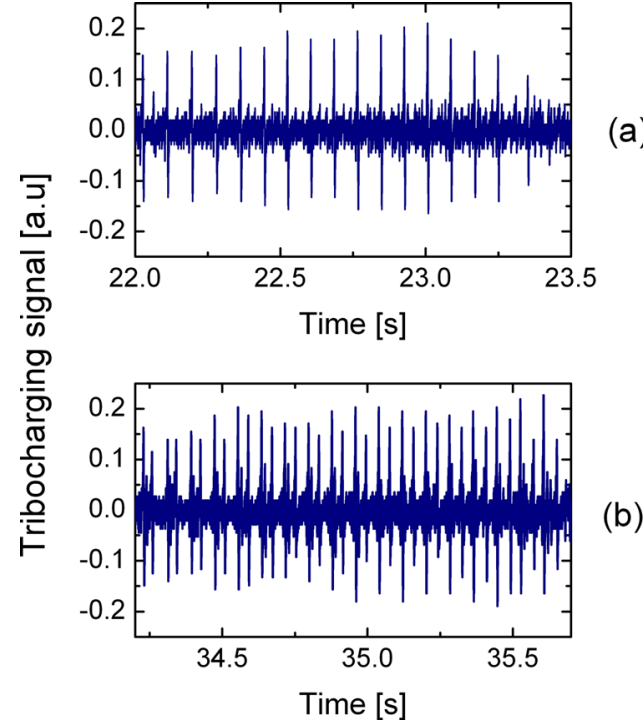

FIG. 7. Zoom-in of Fig. 6 at (a) around $23.3 \mathrm{~s}$; shows increase in signal strength and with two noticeable bipolar signal per cycle before the slow charge decay. (b) Around $35.6 \mathrm{~s}$; shows increase in signal strength as well as threefold increase (compared to region around $23.3 \mathrm{~s}$ ) in the number of bipolar signal per cycle immediately before the instantaneous charge decay.

nisms. Independent to that, a high charge density and an increase in the number of highly charged regions followed by an abrupt fall in signal due to gas breakdown would seem to corroborate each other.

For the applicability of triboplasma/tribocharging we studied their influence on the surface chemistry modification of polyester disks. Here polyester disks were brought in sliding contact with $10 \mathrm{~mm}$ diameter DLC coated steel balls to induce surface modification by tribocharging and/or triboplasma. Polyester surfaces have high affinity to electrons and hence get negatively charged once brought in sliding contact with a relatively better conductor. The electrical conductivity and hardness of a DLC coating depends critically on the $\mathrm{sp}^{3}$ and atomic hydrogen contents. ${ }^{36,37}$ The DLC coating used here is a commercial coating with hardness exceeding 24 $\mathrm{GPa}$, an $\mathrm{sp}^{3}$ content $30 \%$ and an atomic hydrogen content of around $29 \%$. The tribocharging signals obtained by the probe were relatively weak as compared to the glass-Teflon pair. But above all, the signals were hugely perturbed by the dust reaching the sensor face. Keeping in mind these difficulties, here we concentrated on the surface modification studies.

The results of the polyester surface modification obtained using XPS are summarized in Table I. The XPS analysis shows a decreasing trend in the oxygen to carbon $(\mathrm{O} / \mathrm{C})$ ratio with an increase in treatment time $(30 \mathrm{~s}, 60 \mathrm{~s}, 120 \mathrm{~s}$ and $240 \mathrm{~s}) .{ }^{19}$ The change (decrease) in $\mathrm{O} / \mathrm{C}$ ratio on the triboplasma treated surfaces is very marginal. However, with our previous knowledge on such polyester disks, a marginal $(+0.02)$ to as large as $(+0.2)$ increase (rather than decrease) in $\mathrm{O} / \mathrm{C}$ ratio has been recorded; where the increase in $\mathrm{O} / \mathrm{C}$ ratio was associated with the adhesion improvement. ${ }^{3-9}$ Note that (a) the previous plasma treatments on such polyester disks were performed using conventional atmospheric pressure plasmas like dielectric barrier discharge (DBD) and gliding arc; (b) the previous treatments were at relatively high powers 
TABLE I. Elemental analysis on the surface of polyester disks using the survey measurements of X-ray photoelectron spectroscopy (XPS). It also presents the chemical analysis using detailed XPS C1s spectrum.

\begin{tabular}{|c|c|c|c|c|c|c|c|c|c|}
\hline \multirow[b]{2}{*}{$\begin{array}{l}\text { Treatment } \\
\text { time at } 2 \mathrm{~N}\end{array}$} & \multirow[b]{2}{*}{$\mathrm{C} 1 \mathrm{~s} \pm 0.2$} & \multirow[b]{2}{*}{$\mathrm{O} 1 \mathrm{~s} \pm 0.2$} & \multirow[b]{2}{*}{$\mathrm{N} 1 \mathrm{~s} \pm 0.2$} & \multirow[b]{2}{*}{$\mathrm{O} / \mathrm{C}$} & \multicolumn{5}{|c|}{$\mathrm{C} 1 \mathrm{~s}$} \\
\hline & & & & & $\begin{array}{c}\text { A: C-H/C-C at } \\
285 \mathrm{eV}\end{array}$ & $\begin{array}{c}\text { B: C-O-C/ C-OH } \\
\text { at } 286.5 \mathrm{eV}\end{array}$ & $\begin{array}{l}\text { C: carbonyl } \\
\text { at } 288 \mathrm{eV}\end{array}$ & $\begin{array}{l}\text { D: carboxyl } \\
\text { at } 289.5 \mathrm{eV}\end{array}$ & $\begin{array}{l}\text { E: Plasmon } \\
\text { at }>290 \mathrm{eV}\end{array}$ \\
\hline Untreated & 79.6 & 19.1 & 1.3 & 0.24 & 57.68 & 21.49 & 9.39 & 8.47 & 2.96 \\
\hline $30 \mathrm{~s}$ & 79.7 & 19.0 & 1.3 & 0.24 & 57.58 & 22.05 & 9.30 & 8.21 & 2.86 \\
\hline $60 \mathrm{~s}$ & 79.8 & 18.8 & 1.4 & 0.23 & 56.59 & 22.86 & 9.35 & 8.32 & 2.87 \\
\hline $120 \mathrm{~s}$ & 80.3 & 18.2 & 1.5 & 0.22 & 56.39 & 23.88 & 9.31 & 7.81 & 2.61 \\
\hline $240 \mathrm{~s}$ & 81.5 & 17.1 & 1.4 & 0.20 & 56.52 & 23.29 & 9.71 & 7.84 & 2.64 \\
\hline $240 \mathrm{~s}^{*}$ & 79.9 & 18.9 & 1.3 & 0.23 & 57.07 & 22.29 & 9.36 & 8.37 & 2.91 \\
\hline
\end{tabular}

at least above few watts, whereas, we presume that triboplasma could put maximum of a few milliwatts. Furthermore, deconvolution of the $\mathrm{C} 1 \mathrm{~s}$ peak ${ }^{4,6}$ indicates a decrease in the contents corresponding to $\mathrm{C}-\mathrm{H} / \mathrm{C}-\mathrm{C}$ (A) at $285 \mathrm{eV}$ and carboxyl (D) at $289.5 \mathrm{eV}$ with an increase of treatment time; Whereas, $C-\mathrm{O}-\mathrm{C} / C-\mathrm{OH}$ (B) at $286.5 \mathrm{eV}$ increased with increasing treatment time. The decreasing trend of the content of plasmons (E) at $>290 \mathrm{eV}$ might be due to breaking of the aromatic ring of polyester.

As the content of $C-\mathrm{O}-\mathrm{C} / \mathrm{C}-\mathrm{OH}$ increases, that of the carboxyl group decreases, and carbonyl (C) stays almost unchanged. This indicates that the deoxidation is probably due to the removal of oxide domains. Dedicated experiments were performed as follows to affirm that the observed deoxidation is due to the influence of a tribocharge and/or triboplasma, but not due to the mechanical rubbing of the surface at the sliding contact. We performed XPS on the polyester surfaces, which were treated for $240 \mathrm{~s}$ by using a $10 \mathrm{~mm}$ diameter steel ball. The conducting steel ball and the polyester disks will produce negligible tribocharging on the surface. ${ }^{20}$ Further to that, for these experiments we also kept the steel balls grounded to avoid any tribocharging. Hence, we predicted and obtained only negligible change on the surface chemistry as compared to the $240 \mathrm{~s}$ treatment with DLC coated steel balls as shown in Table I.

\section{CONCLUSIONS}

We conclude that tribocharging and/or the triboplasma generated on the polyester disks due to its sliding contact with DLC coated steel balls has modified the polyester surface. The surface treatment effects are marginal, and opposite in character as compared to plasma treatments using DBD or gliding arc. Moreover, such treatments are probably able to remove oxide domains, which are not removed by comparable sliding without charging/discharging. We note that this study is the first attempt ever to perform surface modifications using a triboplasma and the results suggest more detailed and dedicated studies to follow.

We earlier demonstrated the function and applicability of a homebuilt high resolution (-spatial and -temporal) probe. The probe was successfully utilized to study the evolution of the tribocharge on the ball track for a sliding contact between a rotating glass disk and a loaded Teflon ball arrangement. Running-in with two distinct phases was obtained when the virgin surfaces were brought into the sliding contact. The first and initial phase was dominated by strong changes on the surface and was characterized by high bipolar signals, whereas the second phase was characterized by negligibly low signal after which the more noticeable tribocharging started. It was observed that any discontinuity in the sliding contact would not instantly bring the tribocharge to zero on a moving disk in the strong tribocharging phase after the running-in. Once the contact was discontinued, the accumulated tribocharge slowly (in $\mathrm{t}_{1 / 2} \approx 0.7 \mathrm{~s}$ ) decayed either by being neutralized and/or by diffusion on or into the glass disk in atmospheric-air-like surroundings. However, in extended period tribocharging experiments, without any forced discontinuity to the sliding contact, a slow increase in the magnitude of the tribocharge was followed by relatively slow $\left(\mathrm{t}_{1 / 2} \approx 0.4 \mathrm{~s}\right)$ as well as abrupt $\left(\mathrm{t}_{1 / 2} \approx 0.1 \mathrm{~s}\right)$ discharges. The slow discharge could be a result of charge diffusion and/ or neutralization, whereas the abrupt changes might be due to gas breakdown. Though the amplitude of the bipolar signal was similar in the vicinity of slow and abrupt discharges, interestingly, the number of bipolar current before the abrupt discharge per cycle was almost threefold higher than before the slow one. An almost threefold increase in the number of bipolar current per cycle demonstrates a proportionate increase in the highly charged regions on the track. Based on this, we tentatively propose that the charge density has significantly increased along the ball track before the gas breakdown situation as compared to other slow discharge cases. Moreover, independent to that, the high charge density and the increase in highly charged regions followed by an abrupt fall in signal due to gas breakdown corroborate each other.

\section{ACKNOWLEDGMENTS}

This research was carried out under Project No. 27406-0530 supported by the Danish Research Council [Forskningsrådet for Teknologi og Produktion (FTP)]. The skillful technical assistance of Mr. J. H. Holm, Mr. M. Jessen, and Mr. S. R. Nimb was gratefully appreciated. We are grateful to Dr. T. L. Andersen for providing us with the polyester disks for this study. The authors also wish to thank Dr. F. Leipold for his fruitful suggestions.

${ }^{1}$ C. Tendero, C. Tixier, P. Tristant, J. Desmaison, and P. Leprince, Spectrochimica Acta B 61, 2 (2006).

${ }^{2}$ E. Aldea, P. Peeters, H. De Vries, and M. C. M. Van De Sanden, Surf. Coat. Technol. 200, 46 (2005). 
${ }^{3}$ Y. Kusano, S. V. Singh, K. Norrman, J. Drews, F. Leipold, N. Rozlosnik, A. Bardenshtein, and N. Krebs, "Ultrasound enhanced plasma surface modification at atmospheric pressure," Surf. Eng. (to be published). DOI: 10.1179/1743294411Y.000000084.

${ }^{4}$ Y. Kusano, S. V. Singh, K. Norrman, F. Leipold, J. Drews, P. Morgen, A. Bardenshtein, and N. Krebs, J. Adhesion 87, 720 (2011).

${ }^{5}$ Y. Kusano, K. Norrman, J. Drews, F. Leipold, S. V. Singh, P. Morgen, A. Bardenshtein, and N. Krebs, Surf. Coat. Technol. 205, S490 (2011).

${ }^{6}$ Y. Kusano, S. V. Singh, A. Bardenshtein, N. Krebs, and N. Rozlosnik, J. Adhesion Sci. Technol. 24, 1831 (2010).

${ }^{7}$ Y. Kusano, Surf. Eng. 25, 415 (2009).

${ }^{8}$ Y. Kusano, S. Teodoru, F. Leipold, T. L. Andersen, B. F. Sørensen, N. Rozlosnik, P. K. Michelsen, Surf. Coat. Technol. 202, 5579 (2008).

${ }^{9}$ Y. Kusano, H. Mortensen, B. Stenum, P. Kingshott, T. L. Andersen, P. Brøndsted, J.B. Bilde-Sørensen, B. F. Sørensen, and H. Bindslev, Plasm. Proc. Polym. 4, S455 (2007).

${ }^{10} \mathrm{G}$. Heinicke, Tribochemistry (Carl Hanser Verlag, Munich, 1984).

${ }^{11}$ W. R. Harper, Contact and Frictional Electrification (Clarendon, Oxford, 1967).

${ }^{12}$ J. I. Zink, Triboluminescence, Acc. Chem. Res. 11, 289 (1978).

${ }^{13}$ O. D. Tasbaz, R. J. K. Wood, M. Browne, H. E. G. Powrie, and G. Denuault, Wear 230, 86 (1999).

${ }^{14}$ J. Sun, R. J. K. Wood, L. Wang, I. Care, and H. E. G. Powrie, Wear 259, 1482 (2005).

${ }^{15}$ K. Nakayama and H. Hashimoto, Tribology Trans. 38, 35 (1995).

${ }^{16} \mathrm{~K}$. Nakayama and H. Hashimoto, Tribology Int. 29, 385 (1996).

${ }^{17}$ J. E. Booth, K. D. Nelson, T. J. Harvey, R. J. K. Wood, L. Wang, H. E. G. Powrie, and J. G. Martine, Tribology Int. 39, 1564 (2006).

${ }^{18}$ S. Morris, R. J. K. Wood, T. J. Harvey, and H. E. G. Powrie, Wear 255, 430 (2003).

${ }^{19}$ S. V. Singh, Y. Kusano, P. Morgen, and P. K. Michelsen, Triboplasma: generation, characterization and application for surface modification, Conference Book 30th ICPIG (Belfast, UK) http://mpserver.pst.qub.ac.uk/sites/
icpig2011/119_TOP_Singh.pdf (2011); Y. Kusano, S. Taormina, P. K. Michelsen, and K. Nakayama, Triboplasma - its generation and application for surface modification, Proc. 4th Mikkeli Int. Industrial Coating Seminar (Mikkeli, Finland) http://www.miics.net/2008/material/6.2_Kusano/MIICS2008proceeding_Kusano.pdf (2008).

${ }^{20}$ L. S. McCarty and G. M. Whitesides, Angew. Chem. Int. Ed. 47, 2188 (2008).

${ }^{21}$ K. Nakayama and R. A. Nevshupa, J. Phys. D: Appl. Phys. 35, L53 (2002).

${ }^{22}$ K. Nakayama, J. Phys. D: Appl. Phys. 40, 1103 (2007).

${ }^{23}$ G. E. Hardy, J. C. Baldwin, J. I. Zink, W. C. Kaska, P. H. Liu, and L. Duboi, J. Amer. Chem. Soc. 99, 3552 (1977).

${ }^{24}$ K. Nakayama, Wear 194, 185 (1996).

${ }^{25}$ T. Miura and K. Nakayama, Appl. Phys. Lett. 78, 2979 (2001).

${ }^{26}$ R. A. Nevshupa and K. Nakayama, J. Appl. Phys. 93, 9321 (2003).

${ }^{27}$ S. Singh and G.L. Hearn, J. Electrostatics 16, 353 (1985).

${ }^{28}$ K. M. Forward, D. J. Lacks, and R. M. Sankaran, Ind. Eng. Chem. Res. 48, 2309 (2009).

${ }^{29}$ P. J. Blau, Tribology Int. 38, 1007 (2005).

${ }^{30}$ C. Guerret-Piecourt, J. Vallayer, and D. Treheux, Wear 254, 950 (2003).

${ }^{31}$ J. Lowell, J. Phys. D: Appl. Phys. 21, 138 (1998).

${ }^{32}$ A. Labadz and J. Lowell, J. Electr. 26, 251 (1991).

${ }^{33}$ M. S. Jean, S. Hudlet, C. Guthmann, and J. Berger, Eur. Phys. J. B 12, 471 (1999).

${ }^{34}$ W. J. Brennan, J. Lowell, M. C. O'Neill, and P. M. W. Wilson, J. Phys. D: Appl. Phys. 25, 1513 (1992).

${ }^{35}$ E. M. Petrie, Handbook of Adhesives and Sealants (McGraw-Hill, New York, 2006).

${ }^{36}$ C. Matta, O. L. Eryilmaz, M. I. De barros Bouchet, A. Erdemir, J. M. Martin, and K. Nakayama, J. Phys. D: Appl. Phys. 42, 075307 (2009).

${ }^{37}$ S. V. Singh, T. Zaharia, M. Creatore, R. Groenen, K. Van Hege, and M. C. M. van de Sanden, J. Appl. Phys. 107, 013305 (2010). 